THE EFFECTS OF A GRADUATED FITNESS PROGRAMME

Klingberg-Olssen (1967) provide the following data:

1. Decrease in pulse and heart rate and a greater myocardial efficiency.

2. Increase in exercise tolerance with regard to Angina Pectoris.

3. Improvement and lowering of blood pressure.

4. Decreased blood lipids.

5. A large psychological improvement.

6. New collateral circulation and an improvement in cardiac flow.

In view of the fact that the project at Tygerberg Hospital is fairly new, no valid statistics are as yet available, but the patients themselves have a far more positive outlook, are fitter and the majority have lost some weight. All patients agree that the exercise sessions have contributed in a large meassure to their return to a normal life.

\section{ACKNOWLEDGEMENTS}

Dr. F. W. Rabe, Medical Superintendent, Tygerberg Hospital for permission to publish this article.

M. J. Runnalls for the help and encouragement to write this article.

\section{REFERENCES}

1. Bruce, R. A. (1973). Prevention and control of cardiovascular complications, in Exercise Testing and Exercise Training in Coronary Heart Disease, New York and London, Academic Press.

2. Eckstein, R. W. (1957). Effect of exercise and coronary artery narrowing on coronary collateral circulaation, in Circulation Research, 5:3:230.

3. Hacket, T. P. and Cassem, N. H. (1973), Psychological adaption to convalescence in myocardial infarction patients, in Exercise Testing and Exercise Training in Coronary Heart Disease, New York and London, Academic Press.

4. Klingberg-Olssen, K. (1967). Early mobilization by physiotherapy and rehabilitation of patients suffering from myocardial infarction, in Proceedings of the Fifth Congress of the World Confederation for Physical Therapy, 5:509.

5. Lind, A. R. (1967). Muscular factors which determine the cardiovascular responses to sustained and rhythmic exercise, in J. Canad. Med. Ass., 96:706

6. Mason, S. A. (Ed.) (1975). Report of a joint workin party on cardiac rehabilitation, in $J$. Royal Collegd of Physicians of London, 9:4:316.

7. Morgans, C. M. and Buston, W. M. (1972). Supervised circuit-training after myocardial infarction, in Physiother, 58:10:340.

8. Murray, A. (1973). Cardiac survival and rehabilitation in Physiother, 59:12:383.

9. Yan, K. (1974). The physical management of patients with ischaemic heart disease, in Proceedings of the Seventh International Congress of the World Confederation of Physical Therapy, 163.

\title{
The Pinch Gauge
}

HADDON G. B. SPEAKMAN, Ph.D.

Assistant Professor

Department of Physical Therapy

University of Central Arkansas

12th and Marshall Strèts

Little Rock, Arkansas, 72201 and

JOSEPH WEISBERG, M.A.
Assistant Professor
Physical Therapy Program
Coltege of Health Related Professions
Downstate Medical Center
450 Clarkson Avenue
Brooklyn, New York, 11203

\section{CONSTRUCTION}

The pinch gauge can be divided into three parts (Fig. 1). The first part of this instrument is a dial (A) that measures force up to 30 pounds and can be rotated so that the pressure sensitive pointer (B) is directly over zero. In order to facilitate reading there is a passive pointer (C) that is moved by the pressure sensitive pointer during testing. When pressure is released, the pressure sensitive pointer returns to zero but the passive pointer remains over the highest pressure achieved. Before the next test is begun, the passive pointer must be moved back alongside the pressure sensitive pointer by rotating the knob in the center of the dial (D). The second part of this instrument is a handle by which the therapist holds the instrument during testing (E). The most stable grip is with the palmar aspect of the end of the thumb on one side, and the lateral aspect of the index finger between the interphalangeal joints, on the other side. The third 
part of this instrument is a handle $(F)$ by which the part of this instrument is a holds the instrument. On both sides of this handle is a groove that improves grip stability (G).

\section{METHOD}

The instrument is held by the therapist at one end, and with the elbow stabilized on the table the subject grasps the other end using any of the six grips described below. For the first four grips described below the measurement is taken with the patients forearm in the pronated position, and for the remaining two it is in the mid-position. The norms for palmar pre'ension, three point prehension and lateral pinch are based on one trial, 2,3 however ot'er methods can be used to obtain a score, but the norms cannot be used. One such method is to administer three trials of a 2 second duration, with a 15 second rest between each trial, and take the average of the best 2 trials.

The following six prehensile grips can be measured ith this instrument:

1. Tip Pinch: The force is applied by the tip of the index finger on one side of the handle and the tip of the thumb on the other side. With the thumb in the same position, the remaining three fingers can be tested in the same way.

2. Three Point Prehension: The force is applied by the tip of the thumb on one side of the handle and the tips of the index and middle fingers together on the otiner side.

3. Palmar Pinch: (Fig. 2) The force is applied by the palmar aspect of the end of the index finger on one side of the handle and the same surface of the thumb on the other side. With the thumb in the same position, the remaining three fingers can be tested in the same way. ${ }^{4}$

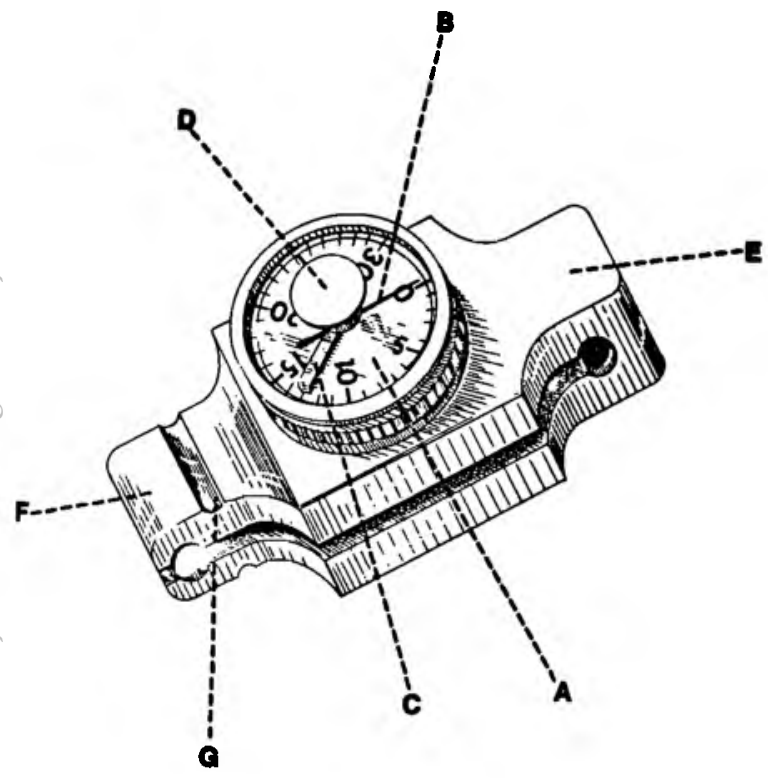

Figure 1. THE PINCH GAUGE

A. dial, B. pressure sensitive pointer, C. passive pointer, D. knob, $\mathbb{E}$. handle for the therapist, $F$. handle for the patient, G. groove.

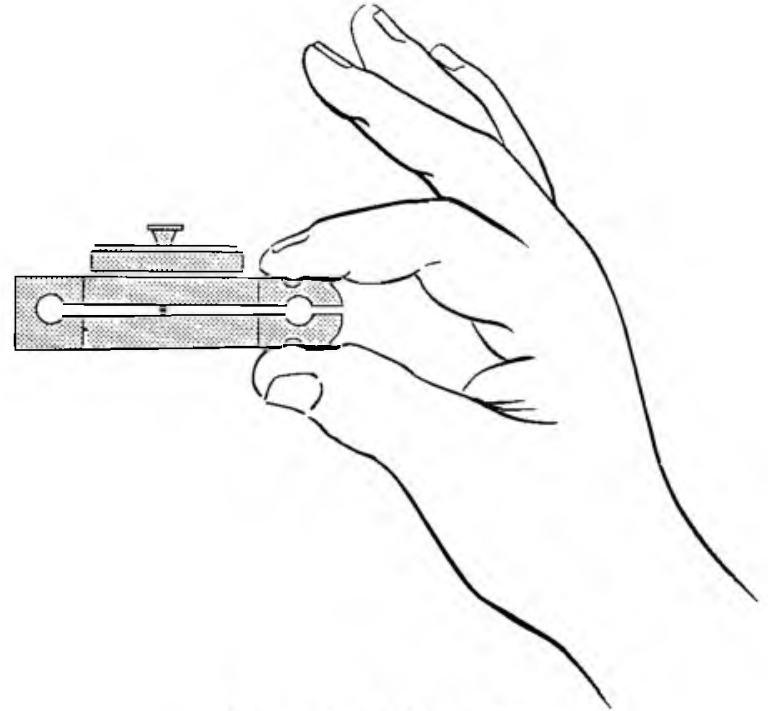

Figure 2. Palmar Pinch.

4. Palmar Prehension: The force is applied by the palmar aspect of the end of the thumb on one side of the handle and the same surface of the index and middle fingers together on the other side. ${ }^{3}$

5. Lateral Pinch: (Fig. 3) The force is applied by the palmar aspect of the end of the thumb on one side of the handle, and the lateral border of the index finger, between the DIP joint and the end of the finger on the other side. ${ }^{3,4}$

6. Finger Squeeze: (Fig. 4) The handle of the instrument is placed between the fingers so the grooves are parallel with their long axes, and the force is applied when the fingers are squeezed together. This is the least useful of the six digital grips because even when hand strength is unimpaired the writer has found that a pressure of 5 pounds is rare.

Progress can be detected in two ways. The first is by comparing the measurement taken on the first day of treatment with those taken later on and the second is by comparing the score obtained by the affected hand with that obtained by the non-affected hand. In the latter method, used only in cases of unilateral disability, the score obtained by affected hand may be recorded as a percentage of the score obtained by the unaffected hand.

The pinch gauge is part of a hand function test that has been developed specially for the evaluation of the congenitally anomalous hand. The two pinches that this test measures are the palmar pinch (all four fingers) and the lateral pinch. 5,6

\section{NORMS}

There are two sources of norms for pinch strength, one for children ${ }^{2}$ and the other for adults. ${ }^{3}$ The norms for children are for the palmar pinch of all four fingers and the lateral pinch. They were obtained by testing a nation-wide sample of 1741 non-handicapped boys and girls with ages ranging from 5 to 13 , and are arranged according to age, sex and laterality. The norms for adults were obtained by measuring the palmar prehension, three point prehension and lateral prehension of 274 nonhandicapped adults. There are separate norms for each sex and hand, and they are divided into 13 consecutive age categories, beginning with $20-24$ years and ending with $80-84$ years. 


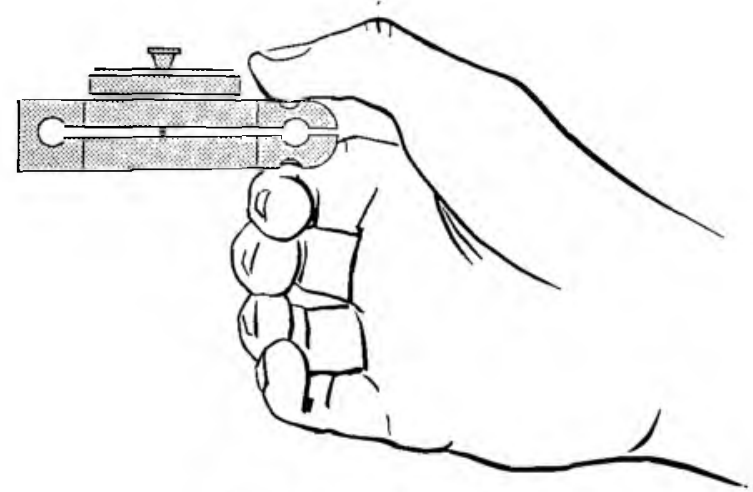

Figure 3. Lateral Pinch.

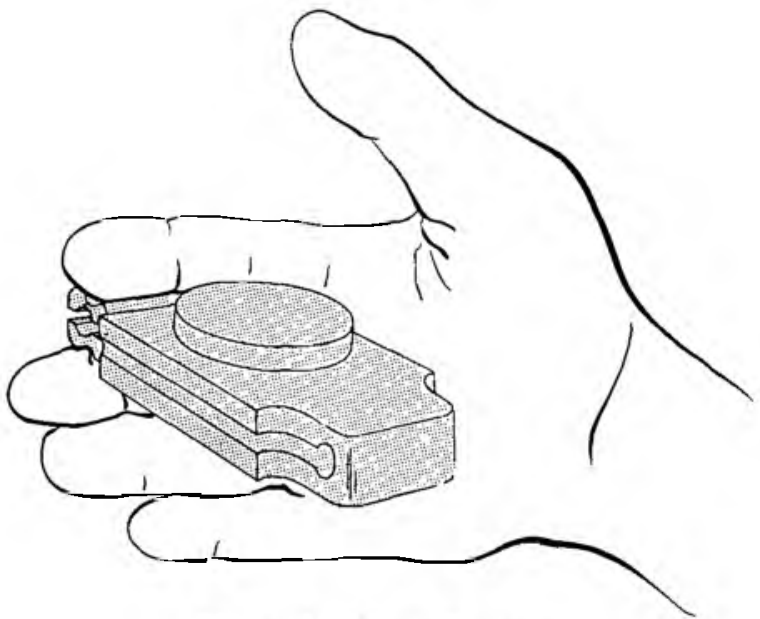

Figure 4. Finger Squeeze.

\section{RESEARCH}

The following three studies report the use of pinch gauge in research projects. Kellor et. al. ${ }^{3}$ measured the palmar prehension, three point prehension, and lateral pinch of 274 non-handicapped volunteers of both sexes that ranged in chronological age from 18 years to over 80. The authors found that (1) pinch strength is a declining function of age; (2) men have greater pinch strength than women and retain this superiority throughout adult life; (3) men loose pinch strength at a greater rate than women. Weiss and Flatt ${ }^{4}$ measured the lateral pinch and the palmar pinch of all four fingers of 198 non-handicapped children ranging in age from 5 to 13 years. The four scores for each subject were totalled to provide a single measure of pinch strength, and a relationship between pinch strength, handedness and digital length was then sought. The results revealed that (1) the right hand was significantly stronger than the left hand in right handed boys and in right handed girls; (2) there were no significant differences between the dominant and nondominant hands of left handed boys and girls; (3) significant correlations between pinch strength and digital length were found for all fingers. Burmeister et. al. ${ }^{2}$ directed a nationwide study that included 1741 children with ages ranging from 5 to 13 years. From each child the following measurements were taken: palmar pinch of all 4 digits, lateral pinch, palm length and width, and length of the 5 digits. Their chief findings were: (1) There were no significant differences in the strengths of the right hands of right-handed boys and the left hands of lefthanded boys. and the left hands of left-handed boys. (2) The index and long finger palmar pinch and lateral pinch of the right hands of right-handed girls was significantly higher than similar measurements for the left hands of left handed girls. (3) The right hand of right handed children was significantly stronger than the left hand on all measurements except the little finger palmar pinch. (4) In left handed children there was no significant difference between the right and left hands in any of the strength measures. (5) There was no significant difference between the non-dominant hands of right and left handed girls. (6) Left handed boys have more strength with their non-dominant hands than right handed boys in index, long, and ring finger palmar pinch. (7) Boys were significantly stronger than girls on all measures. (8) As the children became older their strength improved, although not always from year to year. (9) Pinch strength correlated highly with digit length.

\section{REFERENCES}

1. G. E. Miller Inc. 484 South Broadway, Yonkers, New York, 10705.

2. Burmeister, L. F., Flatt, A. E. and Weiss, M. W. Size and Strength Development of the Hand in Elementary School Children. Iowa City, Iowa: Iowa State Services for Crippled Children, 1974.

3. Kellor, M. et,al. Technical Manual: Hand Strength and Dexterity Tests. Minneapolis, Minnesota: Sister Kenny Institute, 1971.

4. Weiss, M. W. and Flatt, E. A. A Pilot Study of 198 Normal Children Pinch Strength and Hand Size in the Growing Hand. The American Journal of Occupational Therapy. 23:1:10-12, 1971.

5. Skerik, J. K., Weiss, M. W. and Flatt, A. E. Part I: Functional Evaluation of Congenial Hand Anomalies. The American Journal of Occupational Therapy. 25.2.98-104, 1971.

6. Weiss, M. W. and Flatt, A. E. Part II: Functional Evaluation of the Congenitally Anomalous Hand. The American Journal of Occupational Therapy. 25:3:139-143, 1971.

7. Kellor, M. et.al. Hand Strength and Dexterity. The American Journal of Occupational Therapy. 25:2:77$83,1971$.

\section{CONGRESS PROCEEDINGS 1975}

Congress Proceedings have now been distributed. If anyone who ordered a copy and has not received theirs, will they please contact The Secretary, P.O. Box 11151, Johannesburg, immediately. 